\title{
State-of-the-art review of goat TSE in the European Union, with special emphasis on PRNP genetics and epidemiology
}

\author{
Gabriele VACCARI ${ }^{1 \dagger}$, Cynthia H. PANAGIOTIDIS ${ }^{2 \dagger}$, Cristina $\mathrm{ACIN}^{3}$, \\ Simone Peletto ${ }^{4}$, Francis Barillet ${ }^{5}$, Pierluigi Acutis ${ }^{4}$, Alex Bossers ${ }^{6}$, \\ Jan Langeveld ${ }^{6}$, Lucien van KeUlen ${ }^{6}$, Theodoros Sklaviadis ${ }^{2}$, Juan J. Badiola ${ }^{3}$, \\ Olivier AndréOletti ${ }^{5}$, Martin H. Groschup ${ }^{7}$, Umberto Agrimi ${ }^{1}$, James Foster ${ }^{8}$, \\ Wilfred GOLDMANN ${ }^{8 *}$
}

${ }^{1}$ Department of Food Safety and Veterinary Public Health, Unit of Transmissible Spongiform Encephalopathies and Emerging Infectious Diseases of Animals, Istituto Superiore di Sanità, Viale Regina Elena 299, 00161, Rome, Italy

${ }^{2}$ Aristotle University of Thessaloniki, School of Health Sciences, Department of Pharmaceutical Sciences, Laboratory of Pharmacology, Thessaloniki 540 06, Greece

${ }^{3}$ Centro Nacional de Referencia de las EET en España, Facultad de Veterinaria, Universidad de Zaragoza, C/ Miguel Servet 177, 50013 Zaragoza, Spain

${ }^{4}$ Centro di Referenza per le Encefalopatie Animali, Istituto Zooprofilattico Sperimentale del Piemonte, Liguria e Valle d'Aosta, Via Bologna 148, 10154 Turin, Italy

${ }^{5}$ UMR INRA ENVT 1225 Interactions Hôtes Agents Pathogènes, ENVT, 23 Chemin des Capelles, 31076 Toulouse, France

${ }^{6}$ Central Veterinary Institute of Wageningen UR (CVI), Department of Bacteriology and TSEs, PO Box 65, 8200 AB Lelystad, The Netherlands

${ }^{7}$ Institute for Novel and Emerging Infectious Diseases at the Friedrich-Loeffler-Institut, Boddenblick 5a, 17493 Greifswald-Insel Riems, Germany

${ }^{8}$ Roslin Institute and R(D)SVS University of Edinburgh, Roslin, Midlothian, EH25 9PS, United Kingdom

(Received 27 November 2008; accepted 22 May 2009)

\begin{abstract}
Scrapie is a fatal, neurodegenerative disease of sheep and goats. It is also the earliest known member in the family of diseases classified as transmissible spongiform encephalopathies (TSE) or prion diseases, which includes Creutzfeldt-Jakob disease in humans, bovine spongiform encephalopathy (BSE), and chronic wasting disease in cervids. The recent revelation of naturally occurring BSE in a goat has brought the issue of TSE in goats to the attention of the public. In contrast to scrapie, BSE presents a proven risk to humans. The risk of goat BSE, however, is difficult to evaluate, as our knowledge of TSE in goats is limited. Natural caprine scrapie has been discovered throughout Europe, with reported cases generally being greatest in countries with the highest goat populations. As with sheep scrapie, susceptibility and incubation period duration of goat scrapie are most likely controlled by the prion protein $(\operatorname{PrP})$ gene $(P R N P)$. Like the $P R N P$ of sheep, the caprine PRNP shows significantly greater variability than that of cattle and humans.
\end{abstract}

\footnotetext{
These two authors contributed equally to this work.

* Corresponding author: wilfred.goldmann@roslin.ed.ac.uk
}

This is an Open Access article distributed under the terms of the Creative Commons Attribution-Noncommercial License (http://creativecommons.org/licenses/by-nc/3.0/), which permits unrestricted use, distribution, and reproduction in any noncommercial medium, provided the original work is properly cited. 
Although PRNP variability in goats differs from that observed in sheep, the two species share several identical alleles. Moreover, while the ARR allele associated with enhancing resistance in sheep is not present in the goat $P R N P$, there is evidence for the existence of other PrP variants related to resistance. This review presents the current knowledge of the epidemiology of caprine scrapie within the major European goat populations, and compiles the current data on genetic variability of $P R N P$.

\section{transmissible spongiform encephalopathy / prion protein / genetics / goat / scrapie}

\section{Table of contents}

1. Introduction

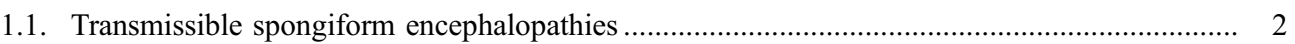

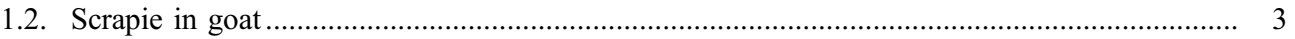

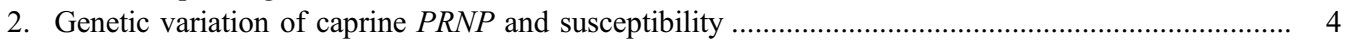

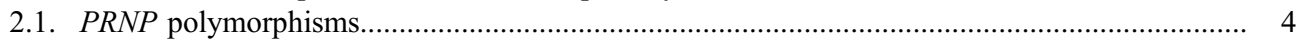

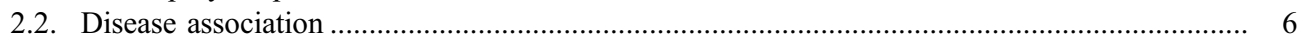

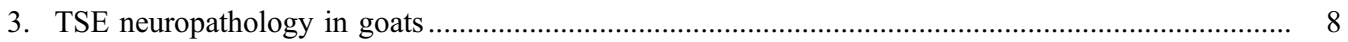

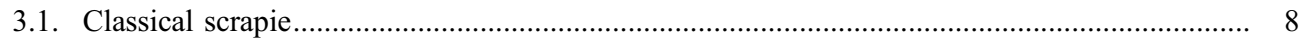

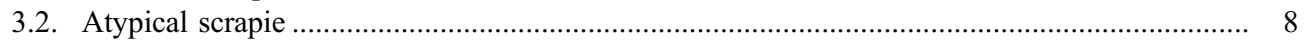

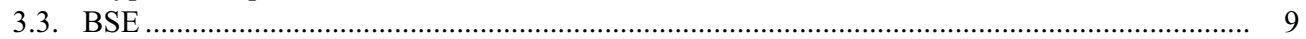

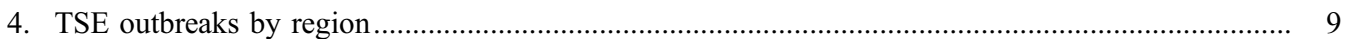

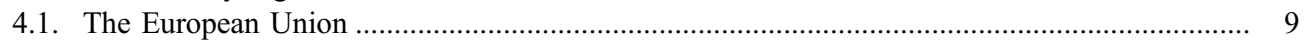

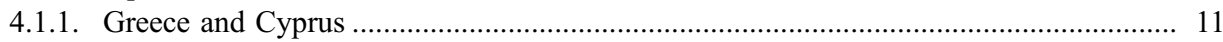

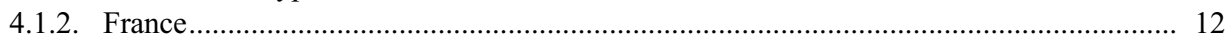

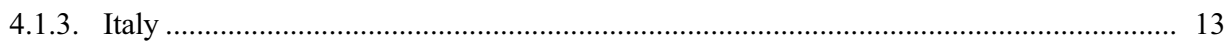

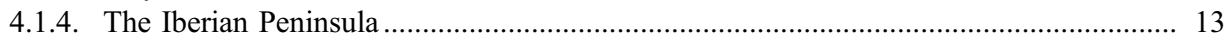

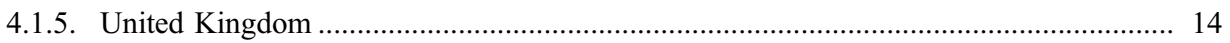

4.1.6. Germany and The Netherlands............................................................................ 14

4.1.7. Other EU member states ............................................................................... 15

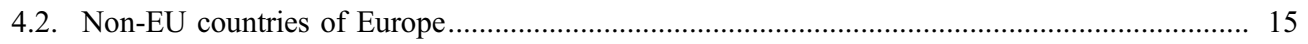

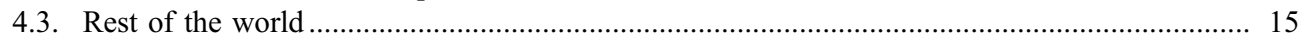

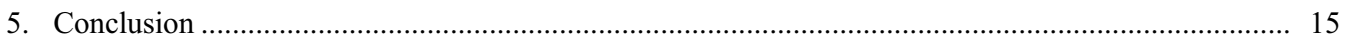

\section{INTRODUCTION}

\subsection{Transmissible spongiform encephalopathies}

Transmissible spongiform encephalopathies (TSE), or prion diseases, are fatal neurodegenerative diseases known to affect many mammalian species, including humans. The TSE of animals include scrapie in sheep and goats, bovine spongiform encephalopathy (BSE) in ruminants, and chronic wasting disease in cervids. Those affecting humans include Creutzfeldt-Jakob disease (CJD), in its sporadic, genetic, variant and iatrogenic forms, as well as Gerstmann-Sträussler-Scheinker syndrome, kuru, and fatal familial insomnia. Experimental and epidemiological evidence associating variant CJD in humans with oral exposure to BSE strongly suggests that transmission of the BSE agent from cattle to people has occurred. In contrast, although scrapie has been known for more than 250 years, there is no equivalent evidence to suggest that a similar natural transmission of the scrapie agent to humans has taken place.

A common feature of the TSE is the accumulation, mainly in the brain, of the pathological prion protein $\left(\mathrm{PrP}^{\mathrm{Sc}}\right)$, an aberrant isoform of the normal, host-encoded cellular prion protein $\left(\mathrm{PrP}^{\mathrm{C}}\right)$. This accumulation is thought to result 
from the conversion of $\operatorname{PrP}^{\mathrm{C}}$ to $\mathrm{PrP}^{\mathrm{Sc}}$ and $\mathrm{PrP}^{\mathrm{Sc}}$ is considered by many to be the infectious agent in TSE [52, 58]. Although the two PrP isoforms share the same amino acid sequence, the alphahelix rich $\mathrm{PrP}^{\mathrm{C}}$ is protease sensitive, while $\mathrm{PrP}^{\mathrm{Sc}}$, with high beta-sheet content, shows partial resistance to proteinase $\mathrm{K}$ digestion. In fact, the rapid tests used to diagnose TSE in ruminants are based on the detection of proteaseresistant $\operatorname{PrP}^{\mathrm{Sc}}$.

$\operatorname{PrP}^{\mathrm{C}}$ is encoded by a single gene $(P R N P)$, which shows considerable amino acid variability in domestic animal populations. Well over 50 single nucleotide polymorphisms (SNP), many giving rise to amino acid changes, have been described in ruminants. Some of these have been associated with varying degree of susceptibility to TSE disease.

Two recent case reports of BSE-like infection in goat, in France and the United Kingdom, have brought this small ruminant species to the attention of prion researchers and European policy makers ${ }^{1}[25,43]$. This review, therefore, aims at summarizing the existing data on TSE in goats, especially for the European Union (EU) situation.

\subsection{Scrapie in goat}

The transmissibility of scrapie to goat was demonstrated just a few years before the observation of the first natural case in goat. Both of the two animals, inoculated by the intraocular route, developed the disease after 25-26 months [19]. In another attempt to transmit sheep scrapie to goats by the intracerebral route [55] all the 12 inoculated goats, developed the disease between 15 and 22 months. In a summary of 170 goats exposed to a third passage goat scrapie inoculum, Pattison and Millson [57] observed an even wider incubation period range than in the first passage ( 7 to 23 months). This difference of 16 months between the shortest and longest incubation period groups is

\footnotetext{
${ }^{1}$ Simmons M.M., Summary of the STEG opinion on two caprine isolates [on line] (2008) http://www. defra.gov.uk/vla/science/docs/sci_tse_rl_steg1008.pdf [consulted 23 February 2009].
}

highly significant. Interpreted with our current knowledge of $P R N P$ genetics in other animals, these early results already pointed to the existence of caprine PRNP alleles capable of influencing scrapie incubation period.

These studies also demonstrated that goats could provide a scrapie model with high efficiency, $100 \%$ susceptibility. This was quite different from the experience with sheep, where survivors were regularly observed. As these experimental challenges were made before the discovery of the PRNP gene, no information of genotypes is available.

In the 1990s goat experiments again became a focus, as BSE transmissions by intracerebral and oral routes were successful. Interestingly, goats showed slightly longer incubation periods than sheep of equivalent PRNP genotypes [30]. These studies also showed that experimentally induced BSE did not transmit via goat embryos. Furthermore, there was no indication of experimental BSE spreading either as a venereal infection to males used in mating or by maternal transmission to offspring born naturally to experimentally infected donors, although numbers were small [28].

The first observation of natural scrapie in goat dates back to 1942, in France, when it appeared in a symptomatic animal living in a sheep flock where the disease had prevailed for several years [17]. Since then clinical scrapie cases in goats have been recorded throughout Europe and in other regions of the world $[13,40,46,60,62-64,73]$. In general, however, the incidence of scrapie in goats is much lower than in sheep. Since 2002 EU-mandatory TSE active surveillance programs have required the routine testing of large numbers of animals at slaughterhouses and from fallen stock throughout Europe. Consequently, the reported incidence of small ruminant scrapie increased, with significantly greater numbers of scrapie positive (based on $\operatorname{PrP}^{\mathrm{Sc}}$ detection), clinically asymptomatic sheep and goats being identified in addition to clinical scrapie cases. Increases in both the numbers of animals being tested and the sensitivity of the applied diagnostic tests during the past five years have resulted in the detection of many preclinical cases of classical scrapie and have led to the recognition 
of a novel, "atypical" scrapie strain [8] in the European small ruminant population [9, 27]. Additionally, one confirmed case of natural goat BSE has been discovered in France [25] through active surveillance. A retrospective examination of early TSE cases in the UK using a more sensitive diagnostic test has revealed a second possible natural case of goat BSE [43]. Consequently, there are currently three classifications of natural prion diseases affecting goats in Europe. These are distinguished, based on their immunobiochemical characteristics, as classical scrapie, "atypical" scrapie, and BSE [24]. As techniques to discriminate TSE strain types improve, however, it is likely ${ }^{1}$ that additional strains, such as the recently recognized ovine CH1641-like isolates [7], will be identified in goats.

The term atypical scrapie has been formulated to describe those sheep samples, positive at the Bio-Rad TeSeE test but presenting difficulties at the confirmatory test. The first case report of atypical scrapie was the 2003 description of a Norwegian sheep that had died five years earlier, in 1998 (hence its designation as "Nor98") [8]. This was quickly followed by the discovery of similar cases in Germany and France [12]. A recent report from the UK describing a 1989 case of ovine Nor98 highlights the fact that this previously unrecognized form of scrapie may have been present in the European small ruminant population for at least 20 years, if not longer [11]. Moreover the prevalence of atypical scrapie in sheep appears homogeneous across 20 European countries and more uniform than classical scrapie [27]. Nor98 scrapie shows unique pathological characteristics that distinguish it from classical scrapie. As reviewed in [9], the two major diagnostic features are its unusual distribution of $\mathrm{PrP}^{\mathrm{Sc}}$ in tissue sections of the central nervous system (CNS) and the presence in brain digests of unique proteinase K-resistant $\mathrm{PrP}^{\mathrm{Sc}}$ fragments, including a prominent band below $15 \mathrm{kDa}$. The similarity of many cases to the phenotype of Nor98 suggests that this disease is widely distributed, although the heterogeneous nature of "atypical" cases suggests that attempts to classify them all as Nor98 or Nor98-like would be premature.
Recently, atypical scrapie has been detected in goats, as well. Specifically, cases of atypical caprine scrapie have been described in Switzerland [60], France, Spain ${ }^{2}$ and Italy [18, 27]. Although the information on atypical goat scrapie is limited, there is already clear evidence of similarities with the distinctive features observed in sheep. In particular, their occurrence as single cases in the affected herds, the molecular pattern obtained in most goat cases, as well as the distribution of histopathological lesions and $\mathrm{PrP}^{\mathrm{Sc}}$ distribution seen in the CNS, is very similar to that observed in Nor98 sheep [60].

\section{GENETIC VARIATION OF CAPRINE PRNP AND SUSCEPTIBILITY}

\subsection{PRNP polymorphisms}

The PRNP gene of goats has been studied less thoroughly than that of sheep, but increased effort in the past decade has revealed a considerable number of polymorphisms in this species as well. In particular, 25 amino acid substitutions have been described in common and indigenous European goat breeds (see Tab. I). In breeds and populations from outside Europe, these and a few novel PRNP polymorphisms have been described: (China) W102G (indicating the wild-type amino acid, the codon and the variant observed), G127S, H143R, N146S, R154H， R211G， R211Q， I218L， T219I, Q222K, S240P [75, 76]; (Japan) W102G, G127S, I142M, H143R, N146S, R211Q, S240P [45]; (Pakistan) S240P [5]; and (USA) G127S, I142M, H143R, N146S, R154H, R211Q, Q222K, S240P [70]. Summarising Table I, it appears that many of the amino acid polymorphisms occur as yet in only one or two countries. However, 7 out of the 29 reported amino acid changes seem to have worldwide

\footnotetext{
${ }^{2}$ European Commission, Report on the monitoring and testing of ruminants for the presence of transmissible spongiform encephalopathy (TSE) in the EU in 2007 [on line] (2009) http://ec.europa.eu/food/food/ biosafety/bse/preliminary_annual_report_tse2007_en. pdf [consulted 12 March 2009].
} 
Table I. Known caprine $P R N P$ gene polymorphisms ${ }^{\mathrm{a}}$.

\begin{tabular}{|c|c|c|c|}
\hline Polymorphism & $\begin{array}{l}\text { EU countries reported } \\
\text { from }\end{array}$ & $\begin{array}{l}\text { Non-EU countries reported } \\
\text { from }\end{array}$ & $\begin{array}{l}\text { First } \\
\text { reference }\end{array}$ \\
\hline W18R & ES & & t.p. \\
\hline V21A & GR & & {$[10]$} \\
\hline L23P & GR & & {$[10]$} \\
\hline G37V & IT & & {$[4]$} \\
\hline$P 42 P$ & UK, IT, FR, GR & US, CN, JP, PK & {$[33]$} \\
\hline G49S & GR & & {$[10]$} \\
\hline Q101R & UK & & t.p. \\
\hline$Q 101 Q$ & NL & & t.p. \\
\hline W102G & UK & $\mathrm{CN}, \mathrm{JP}$ & [34] \\
\hline K107K & GR & & [10] \\
\hline T110P & IT & & {$[4]$} \\
\hline $\mathrm{V} 125 \mathrm{~V}$ & & $\mathrm{CN}$ & [76] \\
\hline G127S & IT, UK, ES, FR & US, CN, JP & [75] \\
\hline L133Q & IT & & {$[1]$} \\
\hline M137I & IT & & [1] \\
\hline S138S & UK, IT, FR, CY, GR & US, CN, JP, PK & [33] \\
\hline $\mathrm{I} 142 \mathrm{M}$ & UK, FR, ES & US, JP & [33] \\
\hline $\mathrm{I} 142 \mathrm{~T}$ & IT & & [2] \\
\hline II42I & NL & & t.p. \\
\hline H143R & UK, IT, GR, NL & US, CN, JP & [33] \\
\hline N146D & $\mathrm{CY}$ & & [54] \\
\hline N146S & CY, UK & US, CN, JP & {$[75][45]$} \\
\hline $\mathrm{R} 151 \mathrm{H}$ & $\mathrm{CY}$ & & {$[54]$} \\
\hline R154H & GR, IT, ES, CY, FR & US, CN & [10] \\
\hline P168Q & IT, GR, CY & & [10] \\
\hline V179V & $\mathrm{CY}$ & & [54] \\
\hline$D 181 D$ & $\mathrm{CY}$ & & [54] \\
\hline T194P & IT & & {$[2]$} \\
\hline$F 201 F$ & ES & & t.p. \\
\hline$T 202 T$ & IT & & {$[1]$} \\
\hline$K 207 K$ & GR & & [10] \\
\hline R211Q & UK, FR, ES & US, CN, JP & [74] \\
\hline $\mathrm{R} 211 \mathrm{G}$ & & $\mathrm{CN}$ & [76] \\
\hline $\mathrm{I} 218 \mathrm{~L}$ & & $\mathrm{CN}$ & [75] \\
\hline T219I & ES & $\mathrm{CN}$ & [76] \\
\hline$T 219 T$ & IT & & [66] \\
\hline Q220H & FR, CY, GR & & [10] \\
\hline Q222K & IT, FR, UK, ES & US, CN & [4] \\
\hline$Q 222 Q$ & NL & & t.p. \\
\hline G232W & ES & & t.p. \\
\hline$G 232 G$ & IT & & {$[66]$} \\
\hline S240P & IT, FR, UK, GR, ES, CY, NL & US, CN, JP, PK & {$[33]$} \\
\hline
\end{tabular}


distribution (by haplotype ranking, from most common: P240, R143, S127, H154, K222, Q211, M142, S146) and at least 5 of these have been suggested to be associated with TSE susceptibility (see below).

Besides SNP, variation in the number of octapeptide (PHGGGWGQ)/nonapeptide (P[Q/H]GGGGWGQ) repeats have been described for Siberian goats; several individuals carrying a haplotype with a single octapeptide (three repeats in total) in combination with glycine at codon 102 have been reported [34]. Silent mutations have been found in caprine PRNP at codons $42(c c g \rightarrow c c a)$ [33], 107 $(a a g \rightarrow a a a) \quad[10], 125 \quad(g t a \rightarrow g t g) \quad[76], 138$ $(a g c \rightarrow a g t) \quad[33], 179 \quad(g t g \rightarrow g t t) \quad[54], 181$ $(\mathrm{gac} \rightarrow \mathrm{gat})$ [54], $201(\mathrm{ttc} \rightarrow \mathrm{ttt}), 202(\mathrm{acc} \rightarrow a c t)$ [1], $207 \quad(a a g \rightarrow a a a)$ [10], $219 \quad(a c c \rightarrow a c t)$ [66], $231(a g g \rightarrow c g g)$ [75] and $232(g g g \rightarrow g g a)$ [66]. Although they are presumed to be nonfunctional in disease, they may still be of use as genetic markers for specific disease phenotypes.

In goat, unlike sheep, $P R N P$ polymorphisms are not always mutually exclusive. An example is the most common polymorphism, S240P, which leads to the presence in goat populations of two highly frequent haplotypes: one with P240 and one with S240, the latter being homologous to the ovine wild-type PRNP. The other haplotypes generally seem to have arisen by mutations on the background of these two central haplotypes, relating to one or the other by a single amino acid substitution. Exceptions are haplotypes M142-S240, M142P240 and H154-S240, H152-P240 [1, 6, 10, 33, 70]. Furthermore, two haplotypes with a double mutation (V37-K222 and H154-K222) have been reported $[18,66]$.

Sheep and goats share the following nine amino acid polymorphisms: Q101R, G127S, H143R， N146S， R151H， R154H， R211Q, T219I and Q220H. The occurrence of identical amino acid substitutions in goat and sheep, mainly for the $\mathrm{R} 154 \mathrm{H}$ dimorphism, is of great interest, as association with TSE disease would be expected to be at least similar, if not the same.

\subsection{Disease association}

PRNP genetic association with disease is well established for sheep and has led to large scale breeding programs in several EU countries [21]. These programs, aimed at eradicating scrapie from national flocks by breeding for genetic resistance, are also in place to deal with the theoretical risk of BSE in sheep. Classical scrapie in sheep shows very strong association with certain PRNP alleles (as reviewed in [36]), so that the allelic combination of the amino acids A136-R154-R171 (ARR) in homozygous genotypes leads to strong, but not absolute [38], resistance. In contrast, V136R154-Q171 (VRQ) in homozygous genotypes leads to very high susceptibility. Many of the other possible combinations have also been shown to modulate susceptibility and incubation periods for classical scrapie and experimental BSE in sheep [31, 41, 42]. For atypical scrapie in sheep, however, other codon positions, mainly 141 and 154, are of great importance for disease susceptibility [47, 48, 50, 59].

Similar scrapie association studies in goats are far more limited and are often restricted in their statistical significance by the apparently low number of affected animals in passive surveillance $[6,10,54,66]$. This may be changing, however, due to the increase in the detection of $\mathrm{PrP}^{\mathrm{Sc}}$-positive, subclinical animals through active surveillance within the EU countries. Nonetheless, some caprine PRNP haplotypes have been implicated as providing increased resistance to disease development relative to wild-type PRNP. The Q222K polymorphism has been associated with protection from scrapie in two independent Italian studies involving several goat breeds (Maltese, Camosciata, Ionica, and crossed breeds) [1, 66], where no scrapie-positive cases were observed in goats carrying the K222 haplotype. In a French study, involving Alpine and Saanen breeds, the same Q222K polymorphism was also found to be associated with increased disease resistance, although in this study $\operatorname{PrP}^{\mathrm{Sc}}$-positive goats carrying the K222 haplotype as heterozygous animals were found [6]. Additionally, the S146N 
Table II. Currently observed frequency range reported for variant haplotypes associated with partial resistance to scrapie.

\begin{tabular}{lccccc}
\hline & Italy & France & USA & Japan & China \\
\hline M142 & $0.0-28.2^{*}$ & $3.9-8.7$ & $0.0-43.2$ & 4.6 & 0.0 \\
& $(5 / 8)^{* *}$ & $(2 / 2)$ & $(4 / 10)$ & $(1 / 1)$ & $14.3-57.1$ \\
R143 & $0.0-5.4$ & 0.0 & $0.0-10.9$ & 3.0 & $(5 / 5)$ \\
& $(4 / 8)$ & & $(4 / 10)$ & $(1 / 1)$ & $0.0-57.4(1 / 5)$ \\
S146 & 0.0 & 0.0 & $0.0-35.2$ & 1.7 & $7.4-46.6$ \\
D146 & & $(7 / 10)$ & $(1 / 1)$ & $(5 / 5)$ \\
H154 & $0.0-11.3(6 / 8)$ & $0.5-5.4$ & $0.0-1.8$ & 0.0 & 0.0 \\
& & $(2 / 2)$ & $(1 / 10)$ & & 12.7 \\
Q211 & $0.0-13.7(4 / 8)$ & $7.1-18.5$ & $0.0-9.7(5 / 10)$ & $(1 / 1)$ & $0.0-21.7(1 / 5)$ \\
& & $(2 / 2)$ & & 0.0 & \\
K222 & $1.3-17.2(8 / 8)$ & $4.9-7.5$ & $0.0-5.4(2 / 10)$ & & \\
& & $(2 / 2)$ & & &
\end{tabular}

\footnotetext{
* Minimum and maximum percentage frequencies of the haplotype relative to all haplotypes observed in the respective study.

** Number of breeds in which the haplotype has been found out of the total breeds included in the study.
}

polymorphism has been associated with protection from classical scrapie in Damascus or Damascus crossbred goats in Cyprus [54]. It should be noted that the presence of polymorphisms at both codons 146 and 222 in goats from several countries may be valuable for the establishment of a breeding programme for the eradication of scrapie in goats. Although scrapie-affected goats with H154 have been observed, this haplotype has been associated with lower susceptibility to classical scrapie in several different breeds and countries $[6,10$, 54, 66]. Case-control studies from France [6] suggest that the Q211 haplotype is also associated with an increased resistance to classical scrapie. Finally, the polymorphism I142M lengthened the incubation periods of experimental scrapie and BSE in goats [33]. Moreover, with respect to naturally transmitted disease, the M142 haplotype has recently been associated with increased resistance to classical scrapie in a French field study [6].

Bearing in mind the ongoing state of affairs with sheep, where the ARR allele provides strong protection against BSE and classical scrapie, but not significantly against atypical scrapie; there is not yet an equivalent allele for goats. It is most probable that several PRNP alleles are able to provide protection against some TSE strains, albeit with different levels of protection. Therefore, additional goat PRNP genotype profiles from many breeds, scrapie sources and geographic origins are needed to define the precise situation for genetic resistance to goat TSE. More candidate PRNP alleles will probably be identified in goats, as has happened in sheep $[35,67,68]$. However, experimental transmission studies using animals with candidate alleles will be needed to determine the level of protection afforded by each, as well as the possible accumulation of $\mathrm{PrP}^{\mathrm{Sc}}$ in peripheral tissues. Finally, it will be important to confirm their effect in homozygous conditions.

Estimating the frequency of candidate haplotypes in a population is a preliminary step in understanding the feasibility of a selection programme. Studies on PRNP haplotype frequencies in goats in Italy, France, the USA, Japan and China $[6,18,45,70,76]$ have been published so far. The currently observed frequency range (in $\%$ of all alleles) reported for the variant haplotyopes associated with partial resistance to scrapie are summarized in Table II. 
The distribution of some haplotypes seems to be breed specific such that they appear absent in some breeds but occur with significant frequencies in some other.

Atypical scrapie has only recently been recognized in goats but histopathological and immunobiochemical analyses in sheep and goats indicate striking similarities between the two species [60] that may extend to genetic targeting. Thus, it has been demonstrated that in goat, where there are no reported polymorphisms at codon 141, Nor98 cases were clearly related to the presence of the H154 haplotye regardless of the amino acids present at codon 240 [18]. These parallel observations in Nor98 disease phenotype, as well as the genetic targeting in sheep and goats, suggests a common agent-host interaction that is different from classical scrapie.

\section{TSE NEUROPATHOLOGY IN GOATS}

\subsection{Classical scrapie}

In addition to the presence of characteristic clinical signs (reviewed in [44]), a hallmark of classical scrapie is progressive neurodegeneration comprising spongiform changes, gliosis, neuronal death and CNS deposition of $\mathrm{PrP}^{\mathrm{Sc}}$. In one of the first studies concentrating on neuropathological changes in scrapie-affected goats, Zlotnik included a case of natural caprine scrapie along with descriptions of intracerebrally (i.c.)-induced disease [77]. He concluded that areas of the midbrain were most severely affected by vacuolation, both in neuronal cell bodies and interstitial tissue. Degenerative lesions appeared to radiate rostrally from this region to the thalamic nuclei and caudally to the pons, cerebellum and medulla.

In three clinical scrapie cases examined and documented in 1980 by Hadlow et al. [39], the most severe lesions occurred in the brainstem, cerebellum and thalamus. These included vacuolation and other degenerative neuronal changes often associated with astrocytic hypertrophy and neuronal atrophy. A retrospective study of 20 natural caprine scrapie cases by
Wood and Done described vacuolation that, in some instances, was present as far forward as the neocortex and striatum [71]. These findings have been corroborated by studies from Cyprus [65], Italy [13-15], Greece [10, 61] and Great Britain [23]. Generally, comparison of the characteristic histopathologic brain lesion profile associated with classical sheep scrapie shows good agreement between the sheep and goats [72].

The application of immunohistochemical (IHC) staining to detect the presence of $\mathrm{PrP}^{\mathrm{Sc}}$ deposits/accumulation in tissue sections has confirmed a consistent involvement of the caudal medulla in classical scrapie of both goats and sheep. In fact, the presence of $\mathrm{PrP}^{\mathrm{Sc}}$ in the dorsal motor nucleus of the vagus nerve (DMNV) is used as a criterion for the categorisation of classical scrapie in both species [24].

Although studies on peripheral scrapie pathogenesis in goat are few, IHC examination of a single clinical case of classical scrapie featuring a 3-year-old female Angora goat revealed a wide distribution of $\mathrm{PrP}^{\mathrm{Sc}}$ outside the CNS. As seen in ovine scrapie, widespread and prominent deposition of $\mathrm{PrP}^{\mathrm{Sc}}$ was observed in the retina, parasympathetic ganglia of myenteric and submucosal plexuses, Peyer's patches, peripheral lymph nodes, pharyngeal and palatine tonsils [69]. Additionally, $\operatorname{PrP}^{\mathrm{Sc}}$ was detected in lymphoid tissues of both clinically $(\mathrm{N}=11)$ and preclinically $(\mathrm{N}=28)$ scrapieaffected animals in a herd of Ionica goats [66]. Early infectivity distribution studies in goats experimentally inoculated with scrapie $[49,56,57]$ showed that cerebrospinal fluid, sciatic nerve, adrenal gland, salivary gland, spleen, pancreas, muscle and liver contained infectivity as measured by bioassay. In contrast, no infectivity was detected in thyroid gland, blood and urine under the same conditions. Disease pathogenesis in goats appears therefore to be more akin to sheep than cattle.

\subsection{Atypical scrapie}

To date, relatively few cases of atypical scrapie in goats have been identified, and detailed 
descriptions of these are scarce. As with sheep, classical and atypical scrapie in goats are discriminated by the unusual localization of spongiform changes and $\mathrm{PrP}^{\mathrm{Sc}}$ in the $\mathrm{CNS}$ and the novel molecular characteristics of the $\mathrm{PrP}^{\mathrm{Sc}}$ present [9] in atypical scrapie. The most complete description of a caprine atypical scrapie case is the first case report, involving a 12-year-old male goat found dead on a Swiss farm [51, 60]. While severe TSE-specific spongiform changes and gliosis were detected in more rostral brain structures, such as thalamus, midbrain and areas of the cerebral cortex, they were strikingly absent in the medulla oblongata and cerebellar cortex [60]. Immunoblot analysis revealed the molecular characteristics of the $\mathrm{PrP}^{\mathrm{Sc}}$ from this goat to be indistinguishable from Nor98 sheep scrapie samples, but distinct from classical scrapie samples. Finally, histopathology of the retropharyngeal lymph nodes, tonsils and third eyelids was normal and IHC revealed an absence of $\operatorname{PrP}^{\mathrm{Sc}}$ deposition in these tissues [60].

\subsection{BSE}

While there are no neuropathological results for the only confirmed case of naturally transmitted caprine BSE [25], information is available from experimental BSE transmissions carried out in the 1980s. Foster et al. described widespread spongiform changes in the midbrain, thalamus and basal ganglia, but not the cortical ganglia, of goats infected by i.c. challenge [30]. These studies showed a more widespread distribution of $\mathrm{PrP}^{\mathrm{Sc}}$ immunostaining than was evident from vacuolation alone [31]. The brains of goats challenged i.c. with BSE gave $\mathrm{PrP}^{\mathrm{Sc}}$ immunostaining throughout the brain stem, usually involving the DMNV, and extending even to inner layers of the parietal and frontal cortex [29]. Subsequent IHC studies, revealed that scrapie sources $(\mathrm{SSBP} / 1$ and CH1641), in contrast to BSE, induced predominantly intracellular disease-associated PrP [43]. A re-examination of tissue sections from UK archival natural caprine "scrapie" cases with improved IHC techniques led to the discovery of one goat sample with a disease-associated
PrP-lesion profile identical to experimental BSE [43]. Three other cases showed phenotypic variability suggestive of TSE strain variation within the UK goat population [43].

\section{TSE OUTBREAKS BY REGION}

\subsection{The European Union}

The EU goat population currently stands at just over 13 million head ${ }^{3,4,5,6}$ with the majority being concentrated in the more southern regions (Tab. III). The three main goat producing countries in the EU are Greece (37\%), Spain (22\%) and France $(9 \%)^{7}$, which produced a combined total of more than 1.5 million tonnes of goat milk and 59000 tonnes of goat meat in 2006 [26]. Recent enlargement of the EU from 15 to 27 members was accompanied by an appreciable rise in its goat population, most notably due to the herds of Romania, Bulgaria and Cyprus, which together hold more than 1.7 million goats (Tab. III).

In the period since 2002, when mandatory active TSE surveillance went into effect, more

$\overline{3}$ Eurostat, Goats population (annual data) (2009) http://nui.epp.eurostat.ec.europa.eu/nui/show.do? dataset=apro_mt_lsgoat\&lang=en [consulted 12 March 2009].

${ }^{4}$ FAOSTAT, Prodstat, live animals [on line] (2008) http://faostat.fao.org/site/573/DesktopDefault.aspx? PageID=573 [consulted 12 March 2009].

5 SWA, Sheep and goats [on line] (2007) http://www. sva.se/en/Startpage/Engelsk-malgruppsnavigering/ animalhealth/Far-och-get/ [consulted 12 March 2009].

${ }^{6}$ DVFA, Animal Health in Denmark p. 67 [on line] (2007) http://gl.foedevarestyrelsen.dk/ FDir/Publications/2007090/Rapport.pdf [consulted 12 March 2009].

${ }^{7}$ Eurostat, Statistics in focus 67/2008; EU sheep and goat population in December 2007 and production forecasts for 2008 [on line] (2008) http://epp.eurostat.ec.europa.eu/cache/ITY_OFFPUB/ KS-SF-08-067/EN/KS-SF-08-067-EN.PDF [consulted 12 March 2009]. 
Table III. Population size and TSE testing information for goats from the 27 member states of the European Union.

\begin{tabular}{|c|c|c|c|c|}
\hline $\begin{array}{l}\text { Member } \\
\text { state }\end{array}$ & $\begin{array}{c}\text { Goat } \\
\text { population }^{3-6} \\
(\times 1000)\end{array}$ & $\begin{array}{c}\text { TSE tests } \\
\text { performed }^{8} \\
(2002-2007) \\
\end{array}$ & $\begin{array}{c}\text { Positive cases } \\
\text { reported }^{8} \\
(2002-2007)\end{array}$ & $\begin{array}{c}\text { Prevalence }^{*} \\
\text { of TSE } \\
(95 \% \text { CI }) \\
\end{array}$ \\
\hline $\mathrm{BE}$ & 26 & 3268 & 0 & $0.0(0.0-14.1)$ \\
\hline BG & 495.5 & 8029 & 0 & $0.0(0.0-5.3)$ \\
\hline $\mathrm{CZ}$ & 16.6 & 852 & 0 & $0.0(0.0-74.5)$ \\
\hline DK & 22 & 6363 & 0 & $0.0(0.0-8.3)$ \\
\hline $\mathrm{DE}$ & 180 & 25477 & 0 & $0.0(0.0-2.8)$ \\
\hline $\mathrm{EE}$ & 4.0 & 133 & 0 & $0.0(0.0-271.0)$ \\
\hline IE & 7.3 & 446 & 0 & $0.0(0.0-82.7)$ \\
\hline GR & 4931.0 & 37779 & 153 & $54.3(44.5-66.3)$ \\
\hline ES & 2891.6 & 152501 & 43 & $3.0(2.2-4.1)$ \\
\hline FR & 1250.2 & $555 \quad 104$ & 118 & $1.1(0.8-1.4)$ \\
\hline IT & 920.0 & 93539 & 49 & $4.0(2.8-5.6)$ \\
\hline $\mathrm{CY}$ & 368.1 & 18082 & 2807 & $666.0(62.0-710.0)$ \\
\hline LV & 13.0 & 124 & 0 & $0.0(0.0-293.0)$ \\
\hline LT & 19.7 & 131 & 0 & $0.0(0.0-284.0)$ \\
\hline LU & 3.3 & 1326 & 0 & $0.0(0.0-30.8)$ \\
\hline $\mathrm{HU}$ & 67.0 & 1284 & 0 & $0.0(0.0-39.7)$ \\
\hline MT & 6.2 & 155 & 0 & $0.0(0.0-310.0)$ \\
\hline NL & 355 & 71295 & 0 & $0.0(0.0-0.6)$ \\
\hline AT & 60.5 & 6984 & 0 & $0.0(0.0-8.0)$ \\
\hline PL & 143.9 & 884 & 0 & $0.0(0.0-33.8)$ \\
\hline PT & 513.5 & 31265 & 0 & $0.0(0.0-1.8)$ \\
\hline $\mathrm{RO}$ & 865.1 & 618 & 2 & $16.2(3.9-89.8)$ \\
\hline SI & 28.2 & 2031 & 4 & $28.4(11.5-72.6)$ \\
\hline SK & 37.9 & 269 & 0 & $0.0(0.0-143.0)$ \\
\hline FI & 5.4 & 2533 & 8 & $22.5(9.1-57.6)$ \\
\hline SE & 3 & 892 & 0 & $0.0(0.0-61.2)$ \\
\hline UK & 95 & 10818 & 44 & $6.8(3.3-13.2)$ \\
\hline Total & 13329 & 1032182 & 3228 & \\
\hline
\end{tabular}

* Prevalence of TSE positives detected by active monitoring of goats for the period 2005-2007, i.e. the number of positive cases detected by active monitoring per 10000 tests performed are given with their $95 \%$ confidence intervals (in parentheses).

than a million EU goats have been tested for the presence of abnormal $\operatorname{PrP}^{8}$. Half of these tests were carried out in France (Tab. III), in the aftermath of the discovery there of natural caprine BSE [25]. Since 2002, EU member coun-

\footnotetext{
${ }^{8}$ European Commission, Cumulative TSE testing in goats since 2002 [on line] (2008) http://ec. europa.eu/food/food/biosafety/bse/mthly_gt_cml reps_tse2002_en.pdf [consulted 12 March 2009].
}

tries have reported 3292 cases of caprine $\mathrm{TSE}^{8}$, as compared to 15034 cases of ovine scrapie reported during the same period ${ }^{9}$. More than $85 \%$ of these EU goat scrapie cases occurred in Cyprus, an island country where

\footnotetext{
${ }^{9}$ European Commission, Cumulative TSE testing in sheep since 2002 [on line] (2008) http://ec.europa.

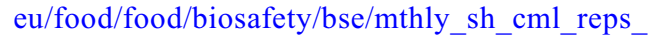
tse2002_en.pdf [consulted 12 March 2009].
} 
classical scrapie is endemic. During the years from 2002 to 2007, 661 (20\%) EU goat TSE cases involved "healthy animals" to be slaughtered for human consumption ${ }^{2,10,11,12,13,14}$. Moreover, since 2004, 33 cases of atypical goat scrapie have been identified in EU member states $^{2}$. Although these latter cases have been relatively few in comparison to the incidence of atypical scrapie in EU sheep (908 cases ${ }^{2}$ ), it is worth noting that in 2007, atypical scrapie cases accounted for at least half the French and Italian caprine TSE cases reported (Fig. 1) and one quarter of Spanish cases.

\subsubsection{Greece and Cyprus}

Currently numbering about 5 million head (Tab. III), the goat population of Greece has

\footnotetext{
${ }^{10}$ European Commission, Report on the monitoring and testing of ruminants for the presence of transmissible spongiform encephalopathy (TSE) in the EU in 2002 [on line] (2003) http://ec.europa.eu/ food/food/biosafety/bse/annual_report 2002 en.pdf [consulted 4 May 2009].

${ }^{11}$ European Commission, Report on the monitoring and testing of ruminants for the presence of transmissible spongiform encephalopathy (TSE) in the EU in 2003 [on line] (2004) http://ec.europa.eu/ food/food/biosafety/bse/annual_report_2003_en.pdf [consulted 4 May 2009].

${ }^{12}$ European Commission, Report on the monitoring and testing of ruminants for the presence of transmissible spongiform encephalopathy (TSE) in the $\mathrm{EU}$ in 2004 [on line] (2005) http://ec.europa.eu/food/ food/biosafety/bse/annual_report_tse2004_en.pdf [consulted 4 May 2009].

${ }^{13}$ European Commission, Report on the monitoring and testing of ruminants for the presence of transmissible spongiform encephalopathy (TSE) in the EU in 2005 [on line] (2006) http://ec.europa. eu/food/food/biosafety/bse/annual_report_tse2005_en. pdf [consulted 4 May 2009].

${ }^{14}$ European Commission, Report on the monitoring and testing of ruminants for the presence of transmissible spongiform encephalopathy (TSE) in the EU in 2006 [on line] (2006) http://ec.europa.eu/food/ food/biosafety/bse/annual_report_tse2006_en.pdf [consulted 4 May 2009].
}

long been the largest in the EU. Approximately $90 \%$ of Greek goats belong to the indigenous Hellenic goats, with the remainder being primarily crosses of this local goat with the Alpine, Toggenburg and Saanen milking breeds of Switzerland. In Greece, about half of the farms with goats hold both goats and sheep and the average number of goats in the mixed herds is about 50, compared to 130 in goat-only herds. The milk from Greek goats is mainly used to produce feta (up to $30 \%$ goat milk) and other types of traditional cheese. The much smaller goat population of Cyprus (368 000 head) comprises three main breeds. Damascus goats $(15 \%)$ and Damascus cross-bred with local goats $(81.7 \%)$ make up the majority and are raised primarily for milk production. Local breeds like the Machaeras goat (1\%), are dual purpose, used for both meat and milk. Of special note, the Cypriot traditional cheese, Halloumi, is produced from the milk of the local goat breeds. In Cyprus, goat-only herds (2 100) and mixed herds of sheep and goats (1 400) both have an average of 80 goats per herd [53]. While Greek goats are mainly kept in traditional extensive systems, especially in the mountainous and semi-mountainous regions [79], very extensive husbandry systems are applied in Cyprus [53].

Epidemiology of goat scrapie - In both Cyprus and Greece, the first cases of scrapie were diagnosed in sheep, in 1985 and 1986, respectively $[46,64]$. Less than a year after its initial scrapie report, Cyprus identified its first confirmed cases of goat scrapie in four dairy goats from one of the original scrapie-affected flocks, which included a few goats as well as sheep [65]. In Greece, where the initial scrapie outbreak was confined to a flock of sheep, goat scrapie was not detected for another eleven years, in a mixed flock of sheep and goats. Since these initial cases, both countries have routinely reported additional cases of goat scrapie, most often in animals from mixed flocks of sheep and goats, and only rarely from herds with only goats. In Cyprus, for example, one study revealed that all but 2 of the 37 farms reporting cases of goat scrapie kept sheep as well as goats, leading the authors to suggest that at least in that country, the dynamics of scrapie 


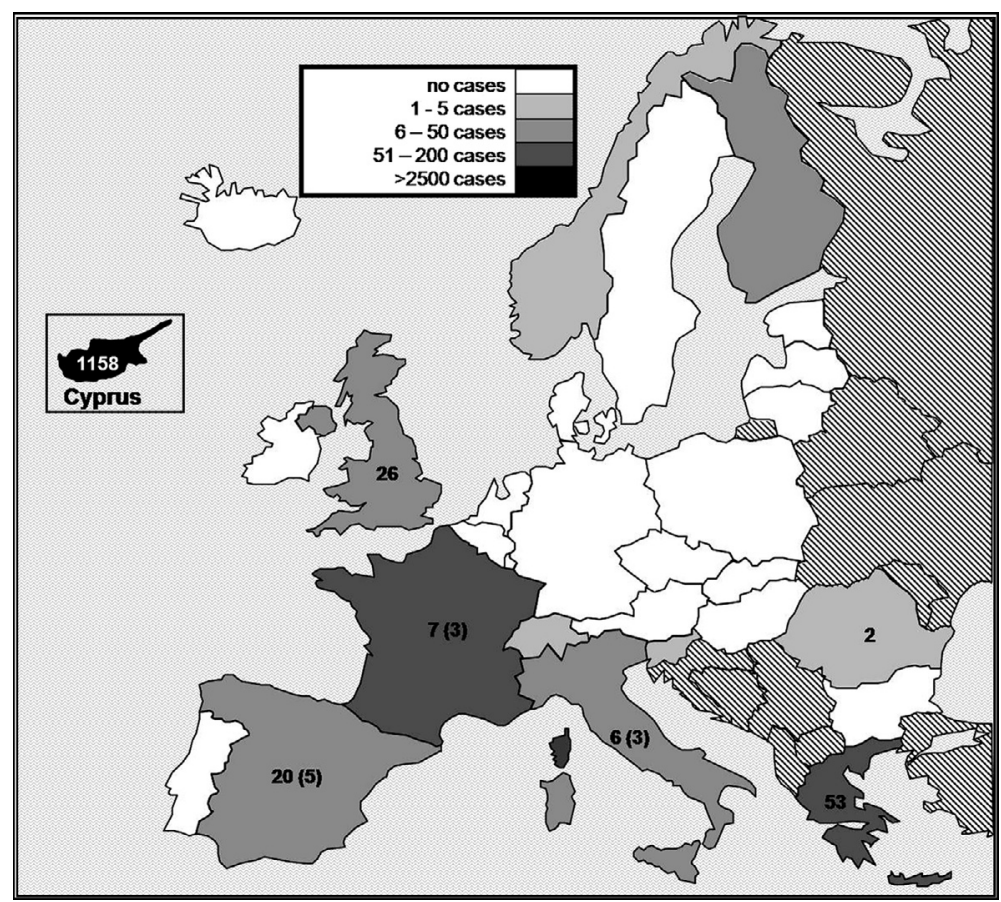

Figure 1. Distribution of goat scrapie cases reported in $27 \mathrm{EU}$ member states, Iceland, Switzerland, and Norway during the period from 2002 to 2007. Numbers outside parentheses indicate the total goat TSE cases reported by individual EU member states in $2007^{8}$, while those inside parentheses indicate the number of atypical goat scrapie cases ${ }^{2}$. Numbers are not shown for countries with no reported cases of goat TSE during 2007. The shading indicates the distribution of goat TSE cases during the period from 2002 to 2007 , according to the scheme outlined in the legend.

in goats is likely to be heavily influenced by the disease in sheep [37].

Cyprus, an island nation where the original scrapie outbreak in 1985 led to an ongoing epidemic affecting both its large sheep population and its goats, has faced an escalating incidence of classical caprine scrapie in recent years, e.g. from 354 cases in 2004 to 1158 cases in $2007^{8}$. The majority of these cases were suspect animals identified through passive TSE surveillance. Greece, in contrast, identifies between 20 and 60 cases of classical goat scrapie annually ${ }^{8}$, primarily through its active monitoring program. With the increased application and improvements in $\mathrm{PrP}^{\mathrm{Sc}}$ testing techniques, reported cases of non-clinical scrapie are no longer rare in Greece and Cyprus. In 2007, for instance, 3 of Greece's 53 reported goat scrapie cases and 254 of the 1158 cases reported by Cyprus were found by active monitoring of healthy goats slaughtered for human consumption ${ }^{2}$.

\subsubsection{France}

The French goat population, which remained stable at just over 1 million head during 2006 and 2007, has increased slowly over the last decade to become the third largest European goat population in 2007. France's 10000 dairy goat herds have an average herd size of 72 animals, but the roughly 2300 herds in the PoitouCharentes region are larger, with an average of 115 goats each. Two main breeds, the French Alpine and French Saanen, represent about $90 \%$ of the total population, which provides 
$31 \%$ of the European goat milk production, making France the largest goat milk producer in Europe ${ }^{7}$. French goat production systems are primarily intensive, but small specialty farms using extensive systems for goat cheese production still exist [22].

Epidemiology of goat scrapie - In France, the first caprine scrapie case in recent years was discovered in 1997 in the framework of a passive surveillance network based on the detection of clinical cases. Beginning in 2002, TSE surveillance switched to an active network based on rapid tests carried out both on animals at abattoirs and on fallen stock. Following the confirmation, in 2005, of a single BSE goat case detected by rapid testing in 2002, exhaustive sampling of French goats, in excess of EU requirements, was performed on both "healthy slaughter" and "fallen stock". To date, although more than half a million French goats have been tested, no new BSE goat cases have been detected. Moreover, the estimated prevalence of atypical scrapie has remained quite stable during the period 2002-2006, being on average 1 in 10000 . The estimated prevalence of classical scrapie, during the same period, ranged from 5.7 to 12 in 100000 animals tested.

\subsubsection{Italy}

The Italian goat population, the fourth largest in the EU, with more than 920000 animals, is concentrated in southern regions and the islands. Officially recognised breeds, with related studbooks, represent $35-40 \%$ of the total population and include Saanen, Camosciata Delle Alpi, Sarda, Maltese, Orobica, Ionica, Girgentana and Garganica goats, which are all raised primarily for milk production. The remainder are rare and mixed breeds, including many endangered Italian breeds such as the Grey Molisana, Istrian, Sempione and Valfortorina goats [20]. In areas like Sardinia, a leading region for goat production in Italy, the herds (about 50 head per herd) are mainly kept in traditional extensive systems, especially in regions where the percentage of cultivable land is very low [22].

Epidemiology of goat scrapie - Since 1997, when the first scrapie cases were described, 50 goat scrapie outbreaks have been reported in Italy, 17 in mixed flocks of goats and sheep and 33 in goat-only herds. While caprine scrapie has been reported nearly all over Italy, the outbreak prevalence in Sicily and Apulia regions is highest. Between 1996 and 1997 a rise was reported in the incidence of scrapie in small ruminants, involving a large number of goat herds and a high mortality [3]. An accidental infection from a vaccine against Mycoplasma agalactiae was presumed to have caused the outbreak [3] and to have been responsible for the involvement of both sheep and goats in same herds, as well as the simultaneous development of the disease in animals of differing ages [15]. While there were no cases of goat scrapie reported in 2000 and 2001, Italy has recorded a total of 49 scrapie cases in the period from 2002 to $2007^{8}$, including 12 reports of atypical scrapie in goats during the past three years ${ }^{2}$. All but 1 of these cases was detected through the Italian active TSE monitoring system for small ruminants.

\subsubsection{The Iberian Peninsula}

Traditionally, goats have been raised for both milk and meat production on the Iberian Peninsula. At 3 million and 513000 head, respectively, the goat populations of Spain and Portugal are the second and sixth largest in the EU (Tab. III). Spain's goats, which produce half a million tonnes of milk annually, are distributed among 35000 farms, many holding both sheep and goats, with an average of 86 goats per herd [22]. In Spain, goats are concentrated in the southern regions, i.e. Andalusia (43\%), Castilla la Mancha $(15 \%)$ and Extremadura (9\%), as well as in the Canary Islands (11\%) [22]. In addition to Alpine and Saanen dairy goats, there are several important local breeds in the Spanish population, including the Murciana, Malagueñ and Verata breeds. Portugal's Serrana, Serpentina and Algarvia goats, which are raised under semi-extensive conditions for milk production, are its most important autochthonous breeds. Goat husbandry in Spain depends on the productive characteristics. In the Andalusian region, for instance, goat farming is generally 
semi-extensive with varying degrees of intensification. Thus, in mountainous regions extensive farming is common, with goats of mixed use or meat-producing breeds being raised in flocks with sheep, while in Málaga province, dairy goats, often of the Malagueñ breed, are raised under more intensive conditions in larger herds, with less dependence on grazing [16].

Epidemiology of goat scrapie - In Spain, when caprine scrapie is detected it is usually found in mixed flocks of sheep and goats, where it affects both species. The first scrapie case in Spain was detected in sheep in 1987 [32]. Fifteen years later, the first goat scrapie outbreak was confirmed in a herd of 110 Alpine dairy goats in Asturias (Northern Spain). The second outbreak, in a mixed flock of sheep (573) and goats (128), was detected in Castilla La Mancha ${ }^{10,11}$. While Spain has reported ten or more goat scrapie cases per year since 2005, Portugal has remained free of caprine scrapie $^{8}$. Portugal, in fact, has no recorded instances of goat scrapie and has only detected sheep scrapie, predominantly atypical cases, since $2003^{2,9}$.

In Spanish caprine scrapie outbreaks the distribution is restricted to those areas of high goat population, with approximately half involving mixed herds and half involving goat-only herds. Interestingly, no clinical signs have been observed in any of the scrapie-affected goats diagnosed in Spain; all the animals were either "fallen stock" or "healthy slaughtered", identified through active TSE monitoring. During 2006 and 2007, a total of 21 classical and 11 atypical scrapie cases were diagnosed in different Spanish goat breeds ${ }^{2,8}$.

\subsubsection{United Kingdom}

The total UK goat population in 2007 was 95000 , up by almost $10 \%$ since $2000^{15}$. Dairy goat numbers in the UK have remained constant at around 33000 over the past two years,

\footnotetext{
15 DEFRA, June Survey of Agriculture and Horticulture [on line] (2008) http://statistics. defra.gov.uk/esg/statnot/june_uk.pdf [consulted 12 March 2009].
}

with the main breeds being British Saanen, British Toggenburg, British Alpine and Anglo Nubian. Sixty per cent are kept in small herds for house milk production. The average commercial herd size is 100 to 200 animals, with the largest herd comprising around 3000 goats.

Epidemiology of goat scrapie - Since the occurrence of the first case of natural caprine scrapie in the UK in 1975 [73], clinical classical scrapie cases have been rare. In fact, in the past few years they have only been observed in herds that were already suspect from the active surveillance. Moreover, the active surveillance of 10961 slaughterhouse carcasses revealed 6 classical scrapie positive goats between 2002 and $2008^{16}$. No confirmed cases of atypical scrapie in goats have been reported in the UK.

\subsubsection{Germany and The Netherlands}

While being considered as a "poor man's cow" in the first half of the 20th century, goats became popular for hobbyists in the countryside and for children's farms in urban neighbourhoods. The goat populations in both countries have increased considerably since 1995, due to the rising milk production economy, a consequence, largely, of the production limitations (quotas) for cow's milk enforced in the $\mathrm{EU}^{17}$.

In The Netherlands about $75 \%$ of the goat population comprises specialised goat holdings of 500 to 1000 animals each, which have undergone intensification of farming and economical improvement. The main dairy breed used for milk production is the Saanen goat. Other breeds are Netherlands Landgoat, Spotted goat, Toggenburger goat, and Boerbok goat. In Germany, where the economic production of

\footnotetext{
16 DEFRA, Active TSE surveillance in Great Britain [on line] (2008) http://www.defra.gov.uk/ $\mathrm{vla} /$ science/docs/sci_tse_stats_active.pdf [consulted 12 March 2009].

${ }^{17}$ Centraal Bureau voor de Statistiek, Fewer pigs and cows, more milk goats [on line] (2002) http://www. cbs.nl/en-GB/menu/themas/landbouw/publicaties/ artikelen/archief/2002/2002-1093-wm.htm [consulted 12 March 2009].
} 
dairy goat is rather marginal, about $10 \%$ of the goat population (20000-30000 goats) are mainly held on biologically justified farms which use the German Fawn (70\% of milk production) and Saanen breeds. Other regionally produced breeds in Germany are Toggenburger, Buren, Erzgebirge, Thüringerwald, and German Improved White.

Epidemiology of goat scrapie - Since the start of mandatory active TSE surveillance in Europe in 2002, no caprine scrapie has been detected in either The Netherlands or Germany, despite testing of a combined total of nearly one hundred thousand goats ${ }^{8}$. However, an outbreak was reported in The Netherlands in 2001, when a small urban farm with twelve goats experienced a clinical case of scrapie in a 2-3 year old goat. This case was confirmed as scrapie by discriminatory testing as developed for sheep [63]. Further testing of the remaining sheep and goats held on the farm revealed that four more goats were positive for classical scrapie, but none of the sheep.

\subsubsection{Other $E U$ member states}

In recent years, three additional EU member countries have reported limited cases of goat scrapie. Most recently, in 2007, Romania (865 000 goats) in its first year of TSE reporting (618 tests), discovered two cases of classical goat scrapie: one by active monitoring and one as a suspect case ${ }^{2}$. In 2005, Finland and Slovenia, with relatively smaller goat populations (Tab. III) each reported 4 cases of classical caprine scrapie, involving 3 and 4 herds, respectively. Finland had experienced an earlier outbreak in 2002, at which time 4 goat scrapie cases were found through active monitoring ${ }^{10}$. Eighteen out of the 27 member states have not reported a single case of goat scrapie. It must be noted however that the cumulative total of 33918 TSE monitoring tests performed in the twelve newest EU member states combined, is less than the number carried out by Spain alone in 2007 (38 638 tests). As a consequence, the discovery of TSE cases in countries with low TSE test numbers yields comparatively high calculated prevalence rates and associated 95\% confidence intervals (Tab. III).

\subsection{Non-EU countries of Europe}

Goat scrapie has also been discovered in nonEU countries of Europe. Thus, Switzerland and Norway, both of which have sizable dairy goat populations ${ }^{4}$, have recently reported incidents of caprine scrapie ${ }^{12}$ [60]. Examination of the affected Swiss goats showed atypical lesion patterns and $\mathrm{PrP}^{\mathrm{Sc}}$ distributions strikingly different from those seen with classical scrapie [51, 60] and thus, constituted the first report of atypical scrapie in goats. Similarly, the Norwegian goat was also reported as an atypical scrapie case.

\subsection{Rest of the world}

While producing almost $20 \%$ of the world's goat milk annually, the EU goats represent only about $2 \%$ of the worldwide goat population. Almost $95 \%$ of the world's goats are concentrated in Asia and Africa, often in poorly developed countries. Information on the prevalence of sheep and goat TSE in these countries is not available. Together the populations of China, India, Pakistan, Bangladesh and Sudan account for more than half the world's estimated 850 million goats and they comprise a wide variety of breeds raised for meat, milk and wool production. While sheep scrapie was discovered in India [78], no cases of scrapie in goats have been described in any of these countries.

Elsewhere in the world, neither Australia nor New Zealand has ever recorded cases of caprine scrapie. In North America, however, both Canada and the USA have reported infrequent incidents of caprine scrapie since they encountered their first cases [40, 62]. In the USA, where the goat population is currently estimated at about 3 million, only 25 cases of clinical goat scrapie have been diagnosed since 1990 .

\section{CONCLUSION}

In the EU, very few cases of goat scrapie had been recorded in any member country prior to 2002. Interestingly, in many member states the first reported goat scrapie case was discovered in a mixed flock where scrapie-affected 
sheep had previously been identified. Since 2002, when the active TSE surveillance program commenced, it has become clear that there are three distinct classifications of natural prion diseases affecting EU goats, i.e. classical scrapie, "atypical" scrapie and BSE. At present, classical scrapie is the predominant $(>98 \%$ of all TSE cases) prion disease affecting the EU goat population, with Cyprus experiencing the preponderance of cases (85\%). Excepting Cyprus, most reported caprine scrapie cases occur in countries with large goat populations. Since 2005, when the first cases of "atypical" goat scrapie were identified, this TSE has represented a significant percentage of annual caprine scrapie cases in affected countries (France, Spain and Italy).

More than 25 polymorphisms have been identified in the caprine PRNP gene, with some being common to both sheep and goats. Limited studies on disease association suggest that, at least in specific goat breeds, PRNP polymorphisms at codons 146 and 222 may influence resistance/susceptibility to classical scrapie strains $[1,6,54,66]$. Likewise, recent work analyzing PRNP genotypes associated with "atypical" goat scrapie clearly suggests an influence of the H154 haplotyes in affected goats [18]. It must be noted, however, that the variability of the caprine PRNP gene, combined with the known variety of distinct prion diseases affecting EU goats, provides an unexpected challenge to the development of a feasible breeding programme for scrapie eradication. The application of such breeding programmes in goats could aid similar, ongoing EU efforts to eradicate scrapie from its sheep population, as scrapie in goats may represent a possible reservoir for sheep. Clearly, a greater knowledge of the caprine PRNP genetic associations with the individual prion diseases is needed if we ever hope to breed for resistance to one prion disease, without inadvertently increasing the susceptibility to another.

Acknowledgements. This work was supported financially by EU projects Neuroprion Network of Excellence (FOOD-CT-2004-506579) and GoatBSE (FOOD-CT-2006-36353), as well as by national funding to individual contributors.

\section{REFERENCES}

[1] Acutis P.L., Bossers A., Priem J., Riina M.V., Peletto S., Mazza M., et al., Identification of prion protein gene polymorphisms in goats from Italian scrapie outbreaks, J. Gen. Virol. (2006) 87:1029-1033.

[2] Acutis P.L., Colussi S., Santagada G., Laurenza C., Maniaci M.G., Riina M.V., et al., Genetic variability of the PRNP gene in goat breeds from Northern and Southern Italy, J. Appl. Microbiol. (2008) 104:1782-1789.

[3] Agrimi U., Ru G., Cardone F., Pocchiari M., Caramelli M., Epidemic of transmissible spongiform encephalopathy in sheep and goats in Italy, Lancet (1999) 353:560-561.

[4] Agrimi U., Conte M., Morelli L., Di Bari M.A., Di Guardo G., Ligios C., et al., Animal transmissible spongiform encephalopathies and genetics, Vet. Res. Commun. (2003) 27 (Suppl. 1):31-38.

[5] Babar M.E., Abdullah M., Nadeem A., Haq A.U., Prion protein gene polymorphisms in four goat breeds of Pakistan, Mol. Biol. Rep. (2009) 36:141-144.

[6] Barillet F., Mariat D., Amigues Y., Faugeras R., Caillat H., Moazami-Goudarzi K., et al., Identification of seven haplotypes of the caprine PrP gene at codons 127, 142, 154, 211, 222 and 240 in French Alpine and Saanen breeds and their association with classical scrapie, J. Gen. Virol. (2009) 90:769-776.

[7] Baron T., Bencsik A., Vulin J., Biacabe A.G., MorignatE., Verchere J., Betemps D., A C-terminal protease-resistant prion fragment distinguishes ovine "CH1641-like" scrapie from bovine classical and L-Type BSE in ovine transgenic mice, PLoS Pathog. (2008) 4:e1000137.

[8] Benestad S.L., Sarradin P., Thu B., Schönheit J., Tranulis M.A., Bratberg B., Cases of scrapie with unusual features in Norway and designation of a new type, Nor98, Vet. Rec. (2003) 153:202-208.

[9] Benestad S.L., Arsac J.N., Goldmann W., Nöremark M., Atypical/Nor98 scrapie: properties of the agent, genetics, and epidemiology, Vet. Res. (2008) 39:19.

[10] Billinis C., Panagiotidis C.H., Psychas V., Argyroudis S., Nicolaou A., Leontides S., et al., Prion protein gene polymorphisms in natural goat scrapie, J. Gen. Virol. (2002) 83:713-721.

[11] Bruce M.E., Nonno R., Foster J., Goldmann W., Di Bari M., Esposito E., et al., Nor98-like sheep scrapie in the United Kingdom in 1989, Vet. Rec. (2007) 160:665-666.

[12] Buschmann A., Biacabe A.G., Ziegler U., Bencsik A., Madec J.Y., Erhardt G., et al., Atypical scrapie cases in Germany and France are identified by discrepant reaction patterns in BSE rapid tests, J. Virol. Methods (2004) 117:27-36.

[13] Capucchio M.T., Guarda F., Isaia M.C., Caracappá S., Di Marco V., Natural occurrence of scrapie in goats in Italy, Vet. Rec. (1998) 143:452-453.

[14] Capucchio M.T., Guarda F., Pozzato N., Coppolino S., Caracappá S., Di Marco V., Clinical signs and diagnosis of scrapie in Italy: a comparative study in sheep and goats, J. Vet. Med. A Physiol. Pathol. Clin. Med. (2001) 48:23-31.

[15] Caramelli M., Ru G., Casalone C., Bozzetta E., Acutis P.L., Calella A., Forloni G., Evidence for the 
transmission of scrapie to sheep and goats from a vaccine against Mycoplasma agalactiae, Vet. Rec. (2001) 148: 531-536.

[16] Castel J.M., Mena Y., Delgado-Pertiñez M., Camùñez J., Basulto J., Caravaca F., et al., Characterization of semiextensive goat production systems in southern Spain, Small Rumin. Res. (2003) 47:133-143.

[17] Chelle P.L.P., Un cas de tremblante chez la chèvre, Bull. Acad. Vet. Fr. (1942) 15:294-295.

[18] Colussi S., Vaccari G., Maurella C., Bona C., Lorenzetti R., Troiano P., et al., Histidine at codon 154 of the prion protein gene is a risk factor for Nor98 scrapie in goats, J. Gen. Virol. (2008) 89:3173-3176.

[19] Cuillé J., Chelle P.L., La maladie dite tremblante du mouton est-elle inoculable?, C. R. Acad. Sci. Paris (1939) 208:1058-1060.

[20] DAD-WWL:3, Domestic Animal Diversity World Watch List, 3rd ed., Part 2, Scherf B.D. (Ed.), Food and Agriculture Organization of the United Nations, Rome, 2000.

[21] Dawson M., Moore R.C., Bishop S.C., Progress and limits of PrP gene selection policy, Vet. Res. (2008) 39:25.

[22] De Rancourt M., Fois N., Lavín M.P., Tchakérian E., Vallerand F., Mediterranean sheep and goats production: An uncertain future, Small Rumin. Res. (2006) 62:167-179.

[23] Dustan B.H., Spencer Y.I., Casalone C., Brownlie J., Simmons M.M., A histopathologic and immunohistochemical review of archived UK caprine scrapie cases, Vet. Pathol. (2008) 45:443-454.

[24] EFSA, Opinion of the scientific panel on biological hazards on the request from the European Commission on classification of atypical transmissible spongiform encephalopathy (TSE) cases in small ruminants, EFSA J. (2005) 276:1-30.

[25] Eloit M., Adjou K., Coulpier M., Fontaine J.J., Hamel R., Lilin T., et al., BSE agent signatures in a goat, Vet. Rec. (2005) 156:523-524.

[26] Eurostat, From farm to fork statistics, European Commission, Luxembourg, 2008.

[27] Fediaevsky A., Tongue S.C., Nöremark M., Calavas D., Ru G., Hopp P., A descriptive study of the prevalence of atypical and classical scrapie in sheep in 20 European countries, BMC Vet. Res. (2008) 4:19.

[28] Foster J., McKelvey W., Fraser H., Chong A., Ross A., Parnham D., et al., Experimentally induced bovine spongiform encephalopathy did not transmit via goat embryos, J. Gen. Virol. (1999) 80:517-524.

[29] Foster J., Goldmann W., Parnham D., Chong A., Hunter N., Partial dissociation of $\operatorname{PrP}(\mathrm{Sc})$ deposition and vacuolation in the brains of scrapie and BSE experimentally affected goats, J. Gen. Virol. (2001) 82:267-273.

[30] Foster J.D., Hope J., Fraser H., Transmission of bovine spongiform encephalopathy to sheep and goats, Vet. Rec. (1993) 133:339-341.

[31] Foster J.D., Parnham D., Chong A., Goldmann W., Hunter N., Clinical signs, histopathology and genetics of experimental transmission of BSE and natural scrapie to sheep and goats, Vet. Rec. (2001) 148:165-171.

[32] García de Jalón J.A., De las Heras M., Balaguer L., Badiola J.J., Enfermedad del prúrigo lumbar (scrapie) en la oveja: diagnóstico en 5 rebaños, Medicina Veterinaria (1987) 4:5-6.

[33] Goldmann W., Martin T., Foster J., Hughes S., Smith G., Hughes K., et al., Novel polymorphisms in the caprine PrP gene: a codon 142 mutation associated with scrapie incubation period, J. Gen. Virol. (1996) 77:2885-2891.

[34] Goldmann W., Chong A., Foster J., Hope J., Hunter N., The shortest known prion protein gene allele occurs in goats, has only three octapeptide repeats and is nonpathogenic, J. Gen. Virol. (1998) 79:3173-3176.

[35] Goldmann W., Houston F., Stewart P., Perucchini M., Foster J., Hunter N., Ovine prion protein variant $\mathrm{A}^{136} \mathrm{R}^{154} \mathrm{~L}^{168} \mathrm{Q}^{171}$ increases resistance to experimental challenge with bovine spongiform encephalopathy agent, J. Gen. Virol. (2006) 87:3741-3745.

[36] Goldmann W., PrP genetics in ruminant transmissible spongiform encephalopathies, Vet. Res. (2008) 39:30.

[37] Gravenor M.B., Papasozomenos P., McLean A.R., Neophytou G., A scrapie epidemic in Cyprus, Epidemiol. Infect. (2004) 132:751-760.

[38] Groschup M.H., Lacroux C., Buschmann A., Lühken G., Mathey J., Eiden M., et al., Classic scrapie in sheep with the ARR/ARR prion genotype in Germany and France, Emerg. Infect. Dis. (2007) 13:1201-1207.

[39] Hadlow W.J., Kennedy R.C., Race R.E., Eklund C.M., Virologic and neurohistologic findings in dairy goats affected with natural scrapie, Vet. Pathol. (1980) 17: 187-199.

[40] Hourrigan J.L., Klingsporn A.L., McDaniel H.A., Riemenschneider M.N., Natural scrapie in a goat, J. Am. Vet. Med. Assoc. (1969) 154:538-539.

[41] Jeffrey M., Martin S., Thomson J.R., Dingwall W.S., Begara-McGorum I., González L., Onset and distribution of tissue PrP accumulation in scrapie-affected Suffolk sheep as demonstrated by sequential necropsies and tonsillar biopsies, J. Comp. Pathol. (2001) 125:48-57.

[42] Jeffrey M., Ryder S., Martin S., Hawkins S.A., Terry L., Berthelin-Baker C., Bellworthy S.J., Oral inoculation of sheep with the agent of bovine spongiform encephalopathy (BSE). 1. Onset and distribution of disease-specific PrP accumulation in brain and viscera, J. Comp. Pathol. (2001) 124:280-289.

[43] Jeffrey M., Martin S., González L., Foster J., Langeveld J.P.M., van Zijderveld F.G., et al., Immunohistochemical features of $\operatorname{PrP}^{\mathrm{d}}$ accumulation in natural and experimental goat transmissible spongiform encephalopathies, J. Comp. Pathol. (2006) 134:171-181.

[44] Konold T., Bone G., Simmons M.M., Dexter G., Moore S.J., Pettitt R.G., Scrapie in goats, Vet. Rec. (2007) 161:395-396.

[45] Kurosaki Y., Ishiguro N., Horiuchi M., Shinagawa M., Polymorphisms of caprine PrP gene detected in Japan, J. Vet. Med. Sci. (2005) 67:321-323.

[46] Leontides S., Psychas V., Argyroudis S., Giannati-Stefanou A., Paschaleri-Papadopoulou E., Manousis T., Sklaviadis T., A survey of more than 11 years of neurologic diseases of ruminants with special reference to transmissible spongiform encephalopathies (TSEs) in Greece, J. Vet. Med. B Infect. Dis. Vet. Public Health (2000) 47:303-309. 
[47] Lühken G., Buschmann A., Brandt H., Eiden M., Groschup M.H., Erhardt G., Epidemiological and genetical differences between classical and atypical scrapie cases, Vet. Res. (2007) 38:65-80.

[48] Moreno C.R., Moazami-Goudarzi K., Laurent P., Cazeau G., Andréoletti O., Chadi S., et al., Which PrP haplotypes in a French sheep population are the most susceptible to atypical scrapie?, Arch. Virol. (2007) 152:1229-1232.

[49] Mould D.L., Dawson A.M., The unsuccessful dialysis of scrapie agent from goat brain and spleen, Res. Vet. Sci. (1970) 11:304-305.

[50] Moum T., Olsaker I., Hopp P., Moldal T., Valheim M., Moum T., Benestad S.L., Polymorphisms at codons 141 and 154 in the ovine prion protein gene are associated with scrapie Nor98 cases, J. Gen. Virol. (2005) 86:231-235.

[51] Nentwig A., Oevermann A., Heim D., Botteron C., Zellweger K., Drögemuller C., et al., Diversity in neuroanatomical distribution of abnormal prion protein in atypical scrapie, PLoS Pathog. (2007) 3:e82.

[52] Noinville S., Chich J.F., Rezaei H., Misfolding of the prion protein: linking biophysical and biological approaches, Vet. Res. (2008) 39:48.

[53] Papachristoforou C., Markou M., Overview of the economic and social importance of the livestock sector in Cyprus with particular reference to sheep and goats, Small Rumin. Res. (2006) 62:193-199.

[54] Papasavva-Stylianou P., Kleanthous M., Toumazos P., Mavrikiou P., Loucaides P., Novel polymorphisms at codons 146 and 151 in the prion protein gene of Cyprus goats, and their association with natural scrapie, Vet. J. (2007) 173:459-462.

[55] Pattison I.H., Gordon W.S., Millson G.C., Experimental production of scrapie in goats, J. Comp. Pathol. (1959) 69:300-312.

[56] Pattison I.H., Millson G.C., Further observations on the experimental production of scrapie in goats and sheep, J. Comp. Pathol. (1960) 70:182-193.

[57] Pattison I.H., Millson G.C., Distribution of the scrapie agent in the tissues of experimentally inoculated goats, J. Comp. Pathol. (1962) 72:233-244.

[58] Prusiner S.B., Prions, Proc. Natl. Acad. Sci. USA (1998) 95:13363-13383.

[59] Saunders G.C., Cawthraw S., Mountjoy S.J., Hope J., Windl O., PrP genotypes of atypical scrapie cases in Great Britain, J. Gen. Virol. (2006) 87:3141-3149.

[60] Seuberlich T., Botteron C., Benestad S.L., Brünisholz H., Wyss R., Kihm U., et al., Atypical scrapie in a Swiss goat and implications for transmissible spongiform encephalopathy surveillance, J. Vet. Diagn. Invest. (2007) 19:2-8.

[61] Sofianidis G., Psychas V., Billinis C., Spyrou V., Argyroudis S., Papaioannou N., Vlemmas I., Histopathological and immunohistochemical features of natural goat scrapie, J. Comp. Pathol. (2006) 135:116-129.

[62] Stemshorn B.W., Un cas de tremblante naturelle chez une chèvre, Can. Vet. J. (1975) 16:84-86.

[63] Thuring C.M.A., Erkens J.H.F., Jacobs J.G., Bossers A., Van Keulen L.J.M., Garssen G.J., et al., Discrimination between scrapie and bovine spongiform encephalopathy in sheep by molecular size, immunoreactivity, and glycoprofile of prion protein, J. Clin. Microbiol. (2004) 42: 972-980.

[64] Toumazos P., First report of ovine scrapie in Cyprus, Br. Vet. J. (1988) 144:98-100.

[65] Toumazos P., Alley M.R., Scrapie in goats in Cyprus, N. Z. Vet. J. (1989) 37:160-162.

[66] Vaccari G., Di Bari M.A., Morelli L., Nonno R., Chiappini B., Antonucci G., et al., Identification of an allelic variant of the goat $\operatorname{PrP}$ gene associated with resistance to scrapie, J. Gen. Virol. (2006) 87:1395-1402.

[67] Vaccari G., D’Agostino C., Nonno R., Rosone F., Conte M., Di Bari M.A., et al., Prion protein alleles showing a protective effect on the susceptibility of sheep to scrapie and bovine spongiform encephalopathy, J. Virol. (2007) 81:7306-7309.

[68] Vaccari G., Scavia G., Sala M., Cosseddu G., Chiappini B., Conte M., et al., Protective effect of the $\mathrm{AT}_{137} \mathrm{RQ}$ and $\mathrm{ARQK}_{176}$ PrP allele against classical scrapie in Sarda breed sheep, Vet. Res. (2009) 40:19.

[69] Valdez R.A., Rock M.J., Anderson A.K., O'Rourke K.I., Immunohistochemical detection and distribution of prion protein in a goat with natural scrapie, J. Vet. Diagn. Invest. (2003) 15:157-162.

[70] White S., Herrmann-Hoesing L., O'Rourke K., Waldron D., Rowe J., Alverson J., Prion gene (PRNP) haplotype variation in United States goat breeds, Genet Sel. Evol. (2008) 40:553-561.

[71] Wood J.L., Done S.H., Natural scrapie in goats: neuropathology, Vet. Rec. (1992) 131:93-96.

[72] Wood J.L., McGill I.S., Done S.H., Bradley R., Neuropathology of scrapie: a study of the distribution patterns of brain lesions in 222 cases of natural scrapie in sheep, 1982-1991, Vet. Rec. (1997) 140:167-174.

[73] Wood J.N., Done S.H., Pritchard G.C., Wooldridge M.J., Natural scrapie in goats: case histories and clinical signs, Vet. Rec. (1992) 131:66-68.

[74] Wopfner F., Weidenhöfer G., Schneider R., von Brunn A., Gilch S., Schwarz T.F., et al., Analysis of 27 mammalian and 9 avian PrPs reveals high conservation of flexible regions of the prion protein, J. Mol. Biol. (1999) 289:1163-1178.

[75] Zhang L., Li N., Fan B., Fang M., Xu W., PRNP polymorphisms in Chinese ovine, caprine and bovine breeds, Anim. Genet. (2004) 35:457-461.

[76] Zhou R.Y., Li X.L., Li L.H., Wang H.Y., Lu J.G., Polymorphism of the PRNP gene in the main breeds of indigenous Chinese goats, Arch. Virol. (2008) 153:979-982.

[77] Zlotnik I., The histopathology of the brain of goats affected with scrapie, J. Comp. Pathol. (1961) 71:444-448.

[78] Zlotnik I., Katiyar R.D., The occurrence of scrapie disease in sheep of the remote Himalayan foot hills, Vet. Rec. (1961) 73:543-544.

[79] Zygoyiannis D., Katsaounis N., Milk yield and milk composition of indigenous goats (Capra prisca) in Greece, Animal Products (1986) 42:365-374. 